\title{
Can Severity of Pulmonary Hypertension Affect Success Rate of Balloon Mitral Commissurotomy?
}

\author{
Bahar Galeshi ${ }^{1}$, Maryam Shojaeifard ${ }^{1}$, Melody Farrashi ${ }^{1}$, Hanifeh Ganji ${ }^{2}$, Sajad Erami ${ }^{3}$, \\ and Behshid Ghadrdoost ${ }^{1}$ \\ ${ }^{1}$ Rajaie Cardiovascular Medical and Research Center \\ ${ }^{2}$ Shahrekord University of Medical Science \\ ${ }^{3}$ Shahid Sadoughi University of Medical Sciences and Health Services
}

December 15, 2021

\begin{abstract}
Introduction: Rheumatic heart disease is responsible for the most prevalent pathological causes of mitral stenosis and is closely coupled with pulmonary hypertension. Balloon mitral commissurotomy as an alternative method for mitral valve replacement leads to a reduction in pulmonary pressure. All grades of pulmonary hypertension usually regress after mitral commissurotomy; however, the insignificant changes of pulmonary artery hypertension following balloon mitral valvuloplasty are not uncommon. Methods: This retrospective observational study was carried out on 160 patients with significant symptomatic mitral stenosis (mitral valve area $[\mathrm{MVA}]<1.5 \mathrm{~cm}^{2}$ ) who underwent successful percutaneous transvenous mitral commissurotomy (PTMC) within 2016-2020 at Shaheed Rajaie Cardiovascular, Medical and Research Center, Tehran, Iran. Results: In this study, 89.4\% of the patients were female, and the mean age of the participants was $47.2 \pm 12.4$ years. Most (74\%) patients presented with dyspnea on exertion functional class II. The mean basic MVA was $1 \pm 0.20 \mathrm{~cm}^{2}$ that increased to $1.43 \pm 0.23 \mathrm{~cm}{ }^{2}$, and the mean basic systolic pulmonary artery pressure (PAP) was $43.84 \pm 11.93 \mathrm{mmHg}$ that decreased to $35.13 \pm 7.7 \mathrm{mmHg}$. Persistent PAP after successful PTMC was observed in $34 \%$ of the patients. This group of patients showed smaller MVA gain and PAP reduction after the procedure. Pulmonary vascular resistance (PVR) $>2$ Wood units was correlated to $91.7 \%$ of the postprocedural success rate. Conclusion: The PTMC plays an important role in the reduction of PAP; nevertheless, the chronicity and severity of PAP can lead to persistent pulmonary hypertension. The assessment of initial PAP and basic PVR can help select patients with more likely intended results.
\end{abstract}

\section{Hosted file}

finally addited 00.9.7 ready for submit.docx available at https://authorea.com/users/368236/ articles/549511-can-severity-of-pulmonary-hypertension-affect-success-rate-of-balloonmitral-commissurotomy

\section{Hosted file}

fig1.docx available at https://authorea.com/users/368236/articles/549511-can-severity-ofpulmonary-hypertension-affect-success-rate-of-balloon-mitral-commissurotomy

\section{Hosted file}

fig2.docx available at https://authorea.com/users/368236/articles/549511-can-severity-ofpulmonary-hypertension-affect-success-rate-of-balloon-mitral-commissurotomy 